\title{
Isolation, Identification And Characterisation Of Dye-Adapted Bacteria From Textile Effluents Mixed With Sewage Released Into The River Amaravathy, Karur, Tamilnadu, India.
}

\author{
A. Karthikeyan ${ }^{1}$ and N. Anbusaravanan ${ }^{2}$ \\ 1Associate Professor of Zoology, Government Arts College (Autonomous), (Affiliated to Bharathidasan \\ University, Tiruchirappalli, India) \\ Thanthonimalai, Karur-639 005, India \\ 2Head (Retd.), Postgraduate and Research Department of Zoology, Periyar EVR College (Autonomous), \\ Tiruchirappalli-620 023, India
}

\begin{abstract}
In Karur, the textile factories discharge millions of litres of untreated effluents into the drains that eventually empty into river, Amaravathy. The release of coloured compound into water bodies is undesirable not only because of their impact on photosynthesis of aquatic plants but also due to the carcinogenic nature of these dyes and their breakdown products. In this work, bacteria capable of decolourising Textile effluents mixed with sewage (TES) were isolated. Based on the results of these various biochemical tests, the isolates were identified. The identification was conformed by 16s rRNA sequencing. They were identified as Bacillus cereus AK1968 and Pseudomonas sp. AKDYE14. The sequences were deposited in GENBANK. The accession numbers were JN689235 and JN674167 respectively.
\end{abstract}

Key words: Karur, Amaravathy, Textile Effluents mixed with Sewage (TES), 16srRNA sequencing, Bacillus cereus, Pseudomonas sp., GENBANK

\section{Introduction}

1.1 Amaravathy river basin at the down stream of Karur Town is severely polluted due to discharge of partially treated effluent by the textile bleaching and dyeing units. At present 487 bleaching and dyeing units are in operation. These bleaching and dyeing units are located on either side of Amaravathy river within $2 \mathrm{Km}$ from the river. By average one unit generates 30 kilo litres per day (KLD) of trade effluent. These units have provided either individual effluent treatment plant (IETP) or joined in common effluent treatment plant (CETP). After treatment the effluent is discharged into river Amaravathy. The total dissolve solids (TDS) in the river discharge is in the range of $5000-10000 \mathrm{mg} / \mathrm{L}$ and the chloride is in the range of $2000-4000 \mathrm{mg} / \mathrm{L}$. Daily $14600 \mathrm{KLD}$ of partially treated effluent is discharged into the river. The effluent reaching the river is in dark brown in colour. During summer period there is no water flow in river, only effluent flow can be noticed. In monsoon period the colour in river water can be noticed up to Kattali where the river confluences with river Cauvery [1].

1.2 Dyes are usually aromatic and heterocyclic compounds and are often recalcitrant, some of them being toxic and even carcinogenic [2]. Many microorganisms are capable of degrading azo dyes, including bacteria, fungi, and yeast [3]. The efforts of isolating dye-degrading bacteria started in the 1970s, when Bacillus subtilis was first isolated in 1977, followed by Aeromonas hydrophila in 1978 and Bacilus cereus in 1980. After that, several other dye-degraders such as Pseudomonas and Aeromonas strains were reported [4] (Banat et al., 1996). Recently, bacterial cultures capable of degrading dyes were listed by Banat et al[4]. Pearce et al. [5] and Forgacs et al. [6]. Numerous studies have demonstrated the ability of bacteria in monoculture to degrade dyes anaerobically and aerobically [4]. The effectiveness of microbial decolorization depends on the adaptability and the activity of selected microorganisms. A highly alkali thermostable Bacillus sp. SF isolated from the wastewater drain of a textile finishing company was found to be capable of degrading an azo dye [7]. An azo dye-reducing, endospore forming bacterium was isolated from textile industry wastewater that can decolorize the azo dye Remazol Black B [8].

1.3 Recently, several researchers have identified single bacterial strains that have very high efficacy for removal of azo dyes. In contrast to mixed cultures, the use of a pure culture has several advantages. These include predictable performance and detailed knowledge on the degradation pathways with improved assurance that catabolism of the dyes will lead to nontoxic end products under a given set of environmental conditions. Another advantage is that the bacterial strains and their activity can be monitored using culture-based or molecular methods to quantify population densities of the bacteria over time. Knowledge of the population density can be extrapolated to quantitative analysis of the kinetics of azo-dye decolourisation and mineralization [9]. Microorganisms have developed enzyme system for the decolourisation and mineralization of azo dyes under certain environmental conditions $[9,10,11]$. Preliminary characterization of the bacterial isolate 
regarding its morphological, biochemical characters and decolourisation activity as well as the molecular identity gives useful information with regard to the further application of strain for various purposes [12]. So, present study was designed to isolate the dye adapted and efficient dye decolourising bacterial strains from their native habitat, the textile effluents mixed with sewage (TES) identify and characterise them.

\subsection{Sample collection}

\section{Materials And Methods}

The untreated textile effluents along with sewage were released into the river Amaravathy by smallscale dyeing industries in Karur. Amaravathy river basin is located between north latitude $10^{\circ} 06^{\prime} 51^{\prime \prime} \mathrm{N}$ and $11^{\circ} 02^{\prime} 10^{\prime \prime} \mathrm{N}$ and longitudes $77^{\circ} 03^{\prime} 24^{\prime \prime} \mathrm{E}$ and $78^{\circ} 13^{\prime} 06^{\prime \prime} \mathrm{E}$ in Tamilnadu, India. Samples were collected in sterile plastic bottles from a place where these textile effluents and sewage (TES) confluence with the river Amaravathy. Samples were transported to the laboratory in an ice-packed chest box within $1 \mathrm{hr}$ of collection.

\subsection{Isolation of bacteria from TES and Screening of bacterial isolates}

One $\mathrm{ml}$ of freshly collected TES was serially diluted $\left(10^{-1}-10^{-3}\right)$ in physiological saline. A loopful of each dilution was inoculated, by streaking onto triplicate set of agar plate containing the basal medium. The basal medium contained $\left(\mathrm{gL}^{-1}\right): \mathrm{NaCl}-0.3, \mathrm{MgSO}_{4} 7 \mathrm{H}_{2} \mathrm{O}-0.42, \mathrm{KCl}-0.29, \mathrm{~K}_{2} \mathrm{HPO} 4-1.27, \mathrm{KH}_{2} \mathrm{PO} 4-0.85$, $\mathrm{NaNO}_{3}-0.42$ and deionised water $1,000 \mathrm{ml}$. Agar No. 1 was added at $1.5 \%(\mathrm{w} / \mathrm{v})$ to prepare solid medium. The plates were incubated at $37^{\circ} \mathrm{C}$ for $24-48 \mathrm{hr}$. Morphologically different colonies B1, B2, B3, B4, and B5 developed were picked separately and inoculated separately into $10 \mathrm{ml}$ liquid broth and incubated at $37^{\circ} \mathrm{C}$ for 24hr. Liquid Broth Medium contained (g/L): Tryptone 10.0, Yeast 1.0, Agar 0.7, $\mathrm{NaCl} 10.0$ \& de-ionized water $1000 \mathrm{ml}$. Both the media used were at $\mathrm{pH} 7.0$. Sterilization was done by autoclaving at $121^{\circ} \mathrm{C}$ at $15 \mathrm{psi}$ for $15 \mathrm{~min}$.

Triplicate set of $100 \mathrm{ml}$ Erlenmeyer flasks each containing $25 \mathrm{ml}$ of TES were inoculated with $1 \mathrm{ml}$ of a 24hr liquid broth culture B1, B2, B3, B4, and B5 separately. Two sets of controls were also set up: positive control consisted of duplicate flasks inoculated with $1 \mathrm{ml}$ of heat-treated cells and negative controls consisted of uninoculated flasks. The flasks were incubated at $37^{\circ} \mathrm{C}$ and observed daily for decolourisation of medium (evidence of degradation) and increase in turbidity (evidence of growth). The cultures showing maximum turbidity and decolourisation were selected on the basis of spectrophotometer readings, identified and used for further studies. Each agar plate (mixed with sterilized TES) was inoculated with a loopful of the culture. Incubation was done at $37^{\circ} \mathrm{C}$ for $24-48 \mathrm{hr}$. Colonies was picked and purified by repeated subculture and Gram stained. Colonies which were distinctly seen were used for various identification tests. Various tests (motility, presence/absence of spore, urease, citrate utilization, hydrogen sulphide production, MR, VP, catalase, oxidase, indole, starch hydrolysis and fermentation of various sugars) were carried out according to the methods of [13] Cruickshank et al. [14] Garrity et al. and [15] Holts et al.

\subsection{6s rRNA sequencing}

Identification of the isolated strain that achieved the best decolourisation was performed by $16 \mathrm{~S}$ rDNA sequence analysis. 16S rRNA gene/DNA was obtained according to [16] Pitcher et al. using TE buffer, Lysozyme, Proteinase K, isopropanol and ethanol. The 16SrRNA gene was amplified by PCR using the specific Primer sequences, the forward primer, 16sF- AGAGTTTGATCMTGGCTCAG and the reverse primer, 16sRAAGGAGGTGWTCCARCC and the DYEnamic ET Dye Terminator Cycle Sequencing Kit for the automated Mega Base 500 system (GE Healthcare) [17]. The sequences were aligned using the CLUSTAL X program and analyzed with the MEGA software 2001 [18, 19]. Evolutionary distances were derived from sequence-pair dissimilarities, calculated as implemented in MEGA, using Kimura's DNA substitution model [20]. The phylogenetic reconstruction was done using the Neighbour Joining (NJ) algorithm, with bootstrap values calculated from 1000 replicate runs, using the routines included in the MEGA software [21].

\section{Results}

Five different colonies B1, B2, B3, B4 and B5 were found to be growing in the medium with TES and they were isolated. On the basis of spectrophotometer readings it was found that the isolates $\mathrm{B} 3$ and $\mathrm{B} 4$ showed maximum hydrolysis whereas B1, B2 and B5 isolates showed only slight hydrolysis in liquid broth (Table 1), thus they were not selected for further study of the dye degradation. The desired bacterial strains with strong decolourising ability on TES, B3 and B4, were isolated from TES and identified. The results of various biochemical characters were given in the Table 2.The colony of bacterial isolate B3 was circular, flat, and smooth. The bacteria of the isolate B3 was a gram positive rod shaped, non-motile and facultative anaerobic spore forming bacteria. The optimum growth temperatures ranged from 30 to $50^{\circ} \mathrm{C}$. They could grow at $\mathrm{pH}$ values of between 4.3 and 9.3. The organism produced heat resistant spores and these might germinate if cooling was too slow. They could hydrolyse casein, gelatin and starch, could reduce nitrate, and could produce 
acid from maltose, mannitol, glucose, fructose and galactose. They showed negative result for indole test, methyl red test, voges-proskauer test, and citrate catalase test.The bacteria of B4 colonies were rod shaped, gram-negative, aerobic, non-spore forming bacteria. B4 species also typically showed a positive result to the catalase test, oxidase test, the absence of gas formation from glucose, indole negative, methyl red negative, Voges-Proskauer test negative, and citrate positive. The bacterial strains B3 and B4 were tentatively identified as Bacillus cereus (Plates 1 to 4) and Pseudomonas sp. (Plates $5 \&$ 6) to respectively by referring to Bergey's Manual of Determinative Bacteriology [15]. Based on the phenotypic and biochemical characteristics and genetic and phylogenetic analysis, the new strains were identified and christened as B.cereus AK1968 and Pseudomonas sp. AKDYE 14. The 16S rDNA sequences of both of these bacteria were deposited in GenBank. The accession numbers were JN689235 and JN674167 respectively.

16s rDNA sequence of Bacillus cereus AK1968

CCGTCAATGGCGGGGCCTGCCTAATTACATGCAAGTCGAGCGAATGGATTAAGAGCTTGCTCTTATGAAGTTAGCGGCGGACGGGTGAGTAAC ACGTGGGTAACCTGCCCATAAGACTGGGATAACTCGGGAAACCGGGGCTAATACCGGATAACATTTTGAACCGCATGGTTCGAAATTGAAAGG CGGCTTCGGCTGTCACTTATGGATGGACCCGCGTCGCATTAGCTAGTTGGTGAGGTAACGGCTCACCAGGCAACGATGCGTAGCCGACCTGAGA GGGTGATCGGCCACACTGGGACTGAGACACGGCCCAGACTCCTACGGGAGGCAGCAGTAGGGAATCTTCCGCAATGGACGAAAGTCTGACGGA GCAACGCCCGTGAGTGATGAAGGCTTTCGGGTCGTAAAACTCTGTTGTTAGGGAAGAACAAGTGCTAGTTGAATAAGCTGGCACCTTGACGGTA CCTAACCAGAAAGCCACGGCTAACTACGTGCCAGCAGCCGCGTAATACGTAGGTGGCAAGCGTTATCCGGAATTATTGGGCGTAAAGCGCGCG CAGGTGGTTTCTTAAGTCTGATGTGAAAGCCCACGGCTCAACCGTGGAGGGTCATTGGAAACTGGGAGACTTGAGGCAGAAGAGGAAAGTGGA ATTCCATGTGTAGCGGTGAAATGCGTAGAGATATGGAGGAACACCAGTGGCGAAGGCGACTTTCTGGTCTGTAACTGACACTGAGGCGCGAAA GCGTGGGGAGCAAACAGATTAGATACCCTGGTAGTCCACGCCGTAAACGATGAGTGCTAAGTGTTAGAGGGTTTCCGCCCTTTAGTGCTGAAGT TTAACGCATTAAGCACTCCGCCTGGGGGAGTACGGCCGCGAGGCTGAAATCAAAGGAATTGACGGGGGCCCGCACCAGCGGTGGAACATTTGG TTTAATTTGAAGCCACGGGGAGAACCTTACCCGGTTTTGAACTTCTTTGGAAACCCTTGGGATTGGGGTTTTCCTTTGGGAGCAAGGTACCGGTG GGGCCAGGGTGTTGTCAGGTTGTGTTGTGAGAAGGTGGGGTAAGTTCCGCAAAGAGGGCAAACCTTGATTTTTGGTGCCCTCCTTAAGGTGGGC AATTTAAGGGGGATGCCGGGGCAAACCGGAGGAAGGTGGGGAAGAAGTCAAATTCTCCTTCCCCTTTTGACCTGGGGTACCCAACTGGTTCAAT GGGAGGTACAAAGAGGTGCAAGACCCGGAGGGGGGGGTAATTTTCTAAAACCGTTTCCGTTTGGGTTGTTGGGTGCAAATTGCCTACCTGAAG GTGGAATTCGTTGTTATTGCGGGTCAGCCTGCCGCGGTGAATAAGTTTCCGGGCCTTGGACACCCCGCCCCTCACCCCCCGGGAGTTTGTACCCC CGAAGTTCGGTGGGGGAACCTTTTTGGAGCCAGCCGCTCTTTTGGTGGACTACGATTTTGG

Sequence Analysis with BLAST : Gb|GQ329658.1; Bacillus cereus 16S ribosomal RNA gene, partial sequence Length=1451; Score $=2167$ bits $(1173)$; Strand=Plus/Plus .

\section{6s rDNA Sequence of Pseudomonas sp. AKDYE14}

AAAATTAGGGGAACCGCCCATAGAGTAACAAGTCCCCCCGAAGGTTAGACTAGCTACTTCTGGAGCAACCCACTCCCATGGTGTGACGGGCGG TGTGTACAAGGCCCGGGAACGTATTCACCGTGACTTCTGATTCACGATTACTAGCGATTCCGACTTCACGCAGTCGAGTTGCAGACTGCGATCC GGACTACGATCGGTTTTATGGGATTAGCTCCACCTCGCGGCTTGGCAACCCTTTGTACCGACCATTGAGCACGTGTGTAGCCCTGGCCGTAAGG GCCATGATGACTTGACGTCATCCCCACCTTCCTCCGGTTTGTCACCGGCAGTCTCCTTAGAGTGCCCACCCGAGGTGCTGGTAACTAAGGACAAG GGTTGGCTCGTTACGGGACTTAACCCAACATCTCACGACACGAGCTGACGACAGCCATGCAGCACCTGTGTCTGAGTTCCCGAAGGCACCAATC CATCTCTGGAAAGTTCTCAGCATGTCAAGGCCAGGTAAGTTCTTCGCGTTGCTTCGAATTAAACCACATGCTCCACCGCTTGTGCGGGCCCCCGT CAATTCATTTGAATTTTAACCTTGCGGGCCGTACTCCCCCGGGCGGTCAACTTAAAGGGGTTAGCCGGCGCACTAAAATCTCCAAGGGTTCCCA ACGGGCTATTTGACATCGTTTTCGGCGTGGGACTACCAGGGTATCCTAATCCCGTTTTGCCCCCCCACGCTTTTGCACCCTCAGTGGTCGGTATC AACTCCAAGGGGTCCCCTTCGCAAACTGGGGGTGTCCTTCCTTTTATCTACACCATTTTAGCGGCCTCCTCAGGAATATTCCAGCCCCCCCCCCT ACCCGCTATTCCTAGTTCCCCCCCGTGTTGGATAGCCGGTCCCCAGGGTTTAAACCCCCGGGGGGGTATTTCACTCCGGACCTTTATACAAACCC CCCTTACACCGCGGTGTTATTACCCTCACATAAATTCCCAAGATATAAAGACACTGTGCTACCCCGTCCCTTATATATCTGCCCTGCG

Sequence Analysis with BLAST : Dbj|AB045280.1; Pseudomonas sp.

HMD H5 for 16S rRNA, partial sequence Length $=1488$

Score $=1232$ bits (667); Strand=Plus/Minus

Table 1 Ranking of bacterial isolates B1, B2, B3, B4 \& B5 by their Dye decolourising ability based on visual identification.

\begin{tabular}{|c|c|c|c|}
\hline S.No. & $\begin{array}{c}\text { Purified } \\
\text { colonies }\end{array}$ & $\begin{array}{c}\text { Ranking of decolourisation in Liquid Broth } \\
\text { Medium }\end{array}$ & Ranking of decolourisation in Basal Medium \\
\hline 1. & B1 & ----- & ------ \\
\hline 2. & B 2 & ++ & + \\
\hline 3. & B 3 & +++ & +++ \\
\hline 4. & B 4 & +++ & +++ \\
\hline 5. & B 5 & ------ & ------ \\
\hline
\end{tabular}

Key: ----no decolourisation + slight decolourisation ++ moderate decolourisation +++ intense decolourisation

Table: 2. Morphological and biochemical characteristics of $B 3$ and $B 4$ colonies isolated from the Textile Effluents mixed with Sewage (TES).

\begin{tabular}{|c|l|c|c|}
\hline \multirow{2}{*}{ S.No. } & \multicolumn{1}{|c|}{ Biochemical Test } & \multicolumn{2}{c|}{ Characteristics of } \\
\cline { 3 - 4 } & & B3 isolate & B4 isolate \\
\hline 1. & Gram staining & + & Rods \\
\hline 2. & Morphology & Rods & + \\
\hline 3. & Motility & + & - \\
\hline 4. & Spore & & \\
\hline
\end{tabular}




\begin{tabular}{|c|c|c|c|}
\hline 5. & Spore position & Terminal & - \\
\hline 6. & Spore shape & Ellipsoidal & - \\
\hline 7. & Indole & - & - \\
\hline 8. & Methyl Red & - & - \\
\hline 9. & Voges-Proskauer & - & - \\
\hline 10. & Citrate test & - & + \\
\hline 11. & Catalase test & - & + \\
\hline 12. & Nitrate Reduction test & + & + \\
\hline 13. & Oxidase test & - & + \\
\hline 14. & Hydrolysis of: & & \\
\hline i) & Casein & + & - \\
\hline ii) & Gelatin & + & - \\
\hline iii) & Starch & + & - \\
\hline iv) & Urea & - & - \\
\hline 15. & Acid from: & & \\
\hline i) & D-Maltose & + & + \\
\hline ii) & Mannitol & + & - \\
\hline iii) & D-Glucose & + & + \\
\hline iv) & D-Fructose & + & + \\
\hline v) & Galactose & + & + \\
\hline
\end{tabular}

\section{Discussion}

16S ribosomal RNA gene sequence of B3 isolate was showing common ancestry with Bacillus cereus 16S rRNA gene with highest similarity. The other neighboring species which were showing high similarity with the 16S rRNA gene of Bacillus sp. B31(2008), Bacillus sp. MSM-S1, Bacillus pseudomycoides strain N14, Bacillus subtilis strain BSF01, Bacillus sp. 00763 and Bacillus sp. EC4. 16S rRNA gene of Clostridium sp. W52, Bacillus thuringiensis strain CMST-MSU-APL 2, Glacial ice bacterium G50-TS3 are distinctly showing similarity to the $16 \mathrm{~S}$ rRNA gene of B3isolate.

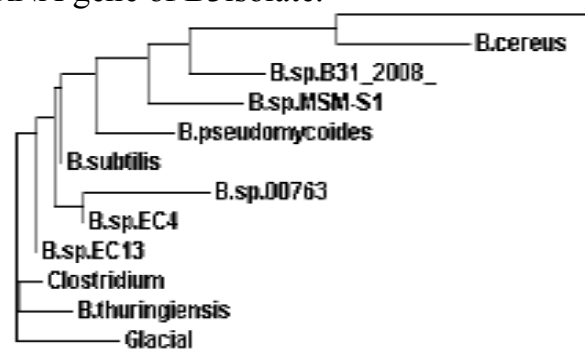

Dendrogram 1. showing the relationship of Bacillus cereus with other bacteria

16S rRNA gene sequence of B4 isolate was showing close evolutionary relationship with Pseudomonas sp. HMD H5 16sRNA gene with highest similarity and sharing common ancestry with the 16S rRNA gene of Pseudomonas sp. V7 and Pseudomonas sp. BWDY-42. 16S ribosomal RNA gene of Pseudomonas sp. K50 and Pseudomonas sp. Y2-1-1, Pseudomonas oleovorans strain DT4 were showing nearest similarity with the 16S rRNA gene of B4 isolate. 16S rRNA gene of Pseudomonas sp. SMCC B0259 and Pseudomonas mendocina strain NaF-C-1 are far distantly similar with 16S rRNA gene of B4 isolate.

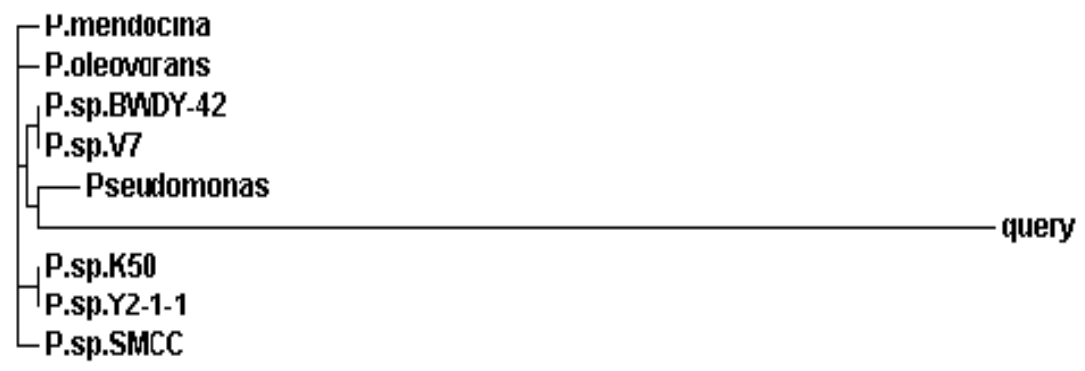

Dendrogram 2. showing the relationship of Pseudomonas sp. with other species 
B. cereus was reported to decolourize cibacron red $\mathrm{P} 4 \mathrm{~B}$ by $81 \%$ using the combination of ammonium nitrate and sucrose and to decolourizes cibacron black PSG by $75 \%$ using yeast extract and lactose. The preliminary decolourisation studies carried out with bacteria species isolated from the dye effluents, indicated that B. cereus performed best when compared to Mycobacterium acidophilus and Streptococcus faecalis [22].

Pseudomonas sp. $(99 \%)$ which has been proved to have decolourising ability against both azo and triphenylmethane dyes [23]. Based on the phenotypic characteristics and phylogenetic analysis, strain was identified as Pseudomonas sp.

Heterotrophic bacteria, such as Escherichia coli, Bacillus sp. Pseudomonos sp., Staphylococcus sp., etc., are usually dominant in the activated sludge system, degrading and eventually mineralizing organic compounds to carbon dioxide and water [24, 25].

A study discovered effluent adapted strains of Acinetobacter, Bacillus and Legionella with potentials for colour removal and strains of Acinetobacter, Bacillus and Pseudomonas with potential use for COD removal. The municipal landfill site soils yielded strains of Bacillus sp. with potentials for use in colour and COD removal. This may be due to the significant exposure of these organisms to a myriad of chemicals and materials some of which contain dyes which are deposited in the landfill which may cause a release of dyes to the soil [25] strain of bacterium Bacillus subtilis with strong decolourising ability was isolated from Textile effluent to decolorize the textile Azo dye Crystal violet $(100 \mathrm{mg} / \mathrm{L})$ within $24 \mathrm{hr}$ in aerobic and static conditions [26]. [27] Khadijah et al reported 1540 bacterial isolates and screened for their ability to degrade selected azo dyes.

Interestingly, the bacterial species used in carrying out the decolorization of Azo dye Crystal violet was isolated from the textile dye industry waste effluent. The bacterial strain Bacillus subtilis showed decolourising activity through a degradation mechanism rather than adsorption. This observation has established that the bacteria are adaptive in nature and can degrade contaminants. The ability of the strain to tolerate, decolorize azo dyes at high concentration gives it an advantage for treatment of textile industry waste waters. However, potential of the strain needs to be demonstrated for its application in treatment of real dye bearing waste waters using appropriate bioreactors[26].

A wild-type isolate Pseudomonas luteola was able to decolorize reactive black B while P. aeruginosa NBAR12 was capable of decolourising 12 different dyes [28]. Pseudomonas aeruginosa was also reported to decolorize certain azo dyes. Many Pseudomonas strains were also found to be capable of denitrification [4]. A total of 24 isolates were obtained; eighteen organisms belonging to the genera, Bacillus, Acinetobacter, Legionella, Staphylococcus and Pseudomonas were isolated from the textile effluents (effluent-adapted bacteria) while six isolates belonging to the genus Bacillus were isolated from the landfill site (effluent non-adapted isolates) [26]. As observed by [3] Chen et al., screening on solid media after adaptation and enrichment gave effective dye decolourising isolates; bacteria colonies with decolourisation zone and fungi showing growth and decolourisation on solid culture which were further picked out and enriched in the liquid media to develop the deferent decolourising consortium. Adapted local microbial isolates from textile wastewater contaminated sites can effectively be used in the aerobic treatment of these effluents before discharging into the environment [29].

Reports indicate that though several microorganisms may seem to have a potential for dye degradation, very few strains can withstand the conditions of dyeing effluents, thus the effluent-adapted strains may be better candidates for potential bioremediative uses [30]. The bacterial isolates Bacillus cereus and Pseudomonas sp. originated from the dye contaminated textile wastewater of local industry can easily adapt to the prevailing local environment. Microbial decolourisation and degradation is an environment friendly and cost-competitive alternative to chemical decomposition processes. Moreover decolourisation and degradation can also detoxify the effluent effectively without leaving any residues [31]. Microbial degradation of azo dyes by extra cellular enzymes in Pseudomonas sp., and Pseudomonas luteola and Mycobacterium avium has already been reported [32]. Indvidual and synergistic effects of B.cereus and Pseudomonas sp. have been proved to be successful in degradation of dye house effluent in dye contaminated ecosystems[33].

\section{Conclusion}

The use of microorganisms like bacteria and fungi for the removal of synthetic dyes from industrial effluent offers considerable advantages. The process is relatively inexpensive, it is simple method and running costs are low, the end products of complete mineralization are not toxic. Therefore, the bacterial strains identified in this work B.cereusAK1968 and Pseudomonas sp.AKDYE14 can be used to develop an effective biological treatment system for the wastewaters contaminated with azo dyes.

\section{References}

[1] R. Rajamanickam and S. Nagan, Groundwater Quality Modeling of Amaravathy River Basin of Karur District, Tamil Nadu, Using Visual Modflow, International Journal of Environmental Sciences, 1(1), 2010, 91-108.

[2] B.Vyas and H.P. Molitoris, Involvement of an extracellular H2O2-dependent ligninolytic activity of the white rot fungus Pleurotus ostreatus in the decolorization of Remazol Brilliant Blue R. Appl Environ Microbiol. 61, 1995, 3919-3927. 
[3] K. Chen, J.Wu, D. Liou, and S.J.Hwang, Decolorization of the textile dyes by newly isolated bacterial strains. Journal of Biotechnology, 101, 2003, 57- 68.

[4] I.M. Banat, P. Nigam, D.Singh, and R. Marchant, Microbial decolorization of textile-dye-containing effluents: a review. Bioresour Technol., 58, 1996, 217-227.

[5] C.I. Pearce, J.R. Lloyd, and J.T. Guthrie, The removal of color from textile wastewater using whole bacterial cells: a review. Dyes and Pigments, 58, 2003, 179-196.

[6] E. Forgacs, T.Cserhati and G. Oros, Removal of synthetic dyes from wastewaters: a review. Environ Int., 30, 2004, 953-71

[7] J. Maier, A. Kandelbauer, A. Erlacher, A.Cavaco-Paulo, G.M. Gubitz, A new alkalithermostable azo reductases from Bacillus sp. Strain SF. Appl Environ Microbiol., 70, 2004, 837-844.

[8] C. Meehan, I.M Banat, G. McMullan, P. Nigam, F. Smyth and R. Marchant, Decolorization of Remazol Black-B using a thermotolerant yeast, Kluyveromyces marxianus IMB3, Environment International, 26(1-2), 2000, 75-79.

[9] A. Khalid, M. Arshad, D.E. Crowley, Accelerated decolorization of structurally different azo dyes by newly isolated bacterial strains. Appl. Microbiol. Biotechnol. 78, 2008, 361-369.

[10] J.J. Hao, F.Q.Song, F. Huang, C.L. Yang, Z.J. Zhang, Y. Zheng, and x.J. Tian, Production of laccase by a newly isolated deuteromycete fungus Pestalotiopsis sp. and its Decolorization of azo dye. Journal of Industrial Microbiology and Biotechnology, 34, 2007, 233-240.

[11] A. Pandey, P. Singh and L. Iyengar, Bacterial decolourisation and degradation of azo dyes. International Biodeterioration and Biodegradation, 59, 2007, 73-84.

[12] M. Grekova-Vasileva1, I.Popov, D. Vassilev, and Y. Topalova1, Isolation and characterisation of capable of azo dye decolourisation, Biotechnol. \& Biotechnol. Eq. 2009, 23.

[13] R. Cruickshank, J.P. Duguid, and R.H.A. Swan, Medical Microbiology $11^{\text {th }}$ ed. (Publ. English Language Book Society and E. \& S. Livingstone, Ltd., Edinburgh. 1980).

[14] G.B.Garrity, J. Don, N.R. Krieg and J.T. Staley, Bergey's manual of systematic bacteriology Vol.2 The Proteobacteria. (Williams and Wilkins. New York, USA, 2005).

[15] G.J. Holts, and D.H. Bergey, Bergey's Manual of Determinative Bacteriology Vol. 1. (Williams and Wikins Co., Baltimore, 1994).

[16] D.G. Pitcher, N.A. Saunders, R.J. Owen, Rapid extraction of bacterial genomic DNA with guanidium thiocyanate. Letters in Applied Microbiology 8, 1989, 151-156.

[17] D.J. Lane, 16S/23S rRNA sequencing. In: Stackebrandt, E., Goodfellow, M. (Eds.), Nucleic Acid Techniques in Bacterial Systematics. John Wiley \& Sons, Chichester, UK, 1991, pp. 115-175.

[18] J.D. Thompson, D.J. Higgins, T.J. Gibson, CLUSTAL W: improving the sensitivity of progressive multiple sequence alignment through sequence weighting, position specific gap penalties and weight matrix choice. Nucleic Acids Research, 22, 1994, 46734680 .

[19] S. Kumar, K. Tamura, and M. Nei, MEGA 3, an integrated software for molecular evolutionary genetics analysis and sequence alignment. Briefings in Bioinformatics, 5, 2004, 150-163.

[20] M. Kimura, A simple method for estimating evolutionary rates of base substitutions through comparative studies of nucleotide sequences. Journal of Molecular Evolution 16, 1980, 111-120.

[21] N.Saitou, and M. Nei, The neighbor-joining method: a new method for reconstructing phylogenetic trees. Molecular Biology and Evolution, 4, 1987, 406-425.

[22] I.O. Ola, A.K. Akintokun, I. Akpan, , I.O. Omomowo, and V.O. Areo, Aerobic decolourisation of two reactive azo dyes under varying carbon and nitrogen source by Bacillus cereus, African Journal of Biotechnology, 9(5), 2011, 672-677.

[23] S.Y. An, S.K. Min, I.H. Cha, Y.L. Choi, Y.S. Cho, C.H. Kim, and Y.C. Lee, Decolorization of triphenylmethane and azo dyes by Citrobacter sp. Biotechnology Letters, 24, 2002, 1037-1040.

[24] V.O. Ajibola, S.J. Oniye, C.E. Odeh, T. Olugbodi, and U.G. Umeh, Biodegradation of Indigo containing textile effluent using some strains of bacteria. Journal of Applied Sciences 5, 2005, 853-855.

[25] O.D. Olukanni, A.A. Osuntoki, and G.O. Gbenle, Textile effluent biodegradation potentials of textile effluent-adapted and nonadapted bacteria, African Journal of Biotechnology, 5(20), 2006, 1980-1984.

[26] S. Kochher and J. Kumar, Microbial Decolourisation of Crystal Violet by Bacillus subtilis, Biological Forum - An International Journal, 3(1), 2011, 82-86.

[27] O. Khadijah, K. Lee, K. Mohd Faiz and F. Abdullah, Isolation, screening and development of local bacterial consortia with azo dyes decolourising capability, Malaysian Journal of Microbiology, 5(1), 2009, 25-32.

[28] M.S. Yeh, and J.S. Shang, Bacterial decolorization of an azo dye with a natural isolate of Pseudomonas luteola and genetically modified Escherichia coli. J Chem Technol Biotechnol. 79, 2004, 1354-1360.

[29] N.P. Ndasi, Mbawala Augustin, Tchatchueng Jean Bosco, Biodecolourisation of textile dyes by local microbial consortia isolated from dye polluted soils in ngaoundere (Cameroon), International Journal of Environmental Sciences, 1(7), 2011, $1403-14$.

[30] S. Rajeshwari, C. Agnes Mariya Dorthy, and R. Venckatesh, Isolation, Characterization and Growth Kinetics of Bacteria Metabolizing Textile Effluent, Journal of Bioscience And Technology, 2011, 324.

[31] P. Verma and D. Madamwar, Decolorization of synthetic dyes by a newly isolated strain of Serratia marcescers. World Journal of Microbiology \& Biotechnology, 19, 2003, 615-618.

[32] N.A. Oranusi, and C.J. Ogugbue, "Effect of $\mathrm{pH}$ and Nutrient Starvation on Biodegradation of Azo Dyes by Pseudomonas sp.", Journal of Applied Sciences \& EnvironmentalManagement, 9(1), 2005, 39-43.

[33] A. Karthikeyan, and N. Anbusaravanan, Biodegradation of Dye House Effluent by the Dye Adapted Strains of Bacteria Bacillus cereus AK1968 and Pseudomonas sp. AKDYE14, International Journal of Applied Biotechnology and Biochemistry. 2(1), 2012, 47-57. 

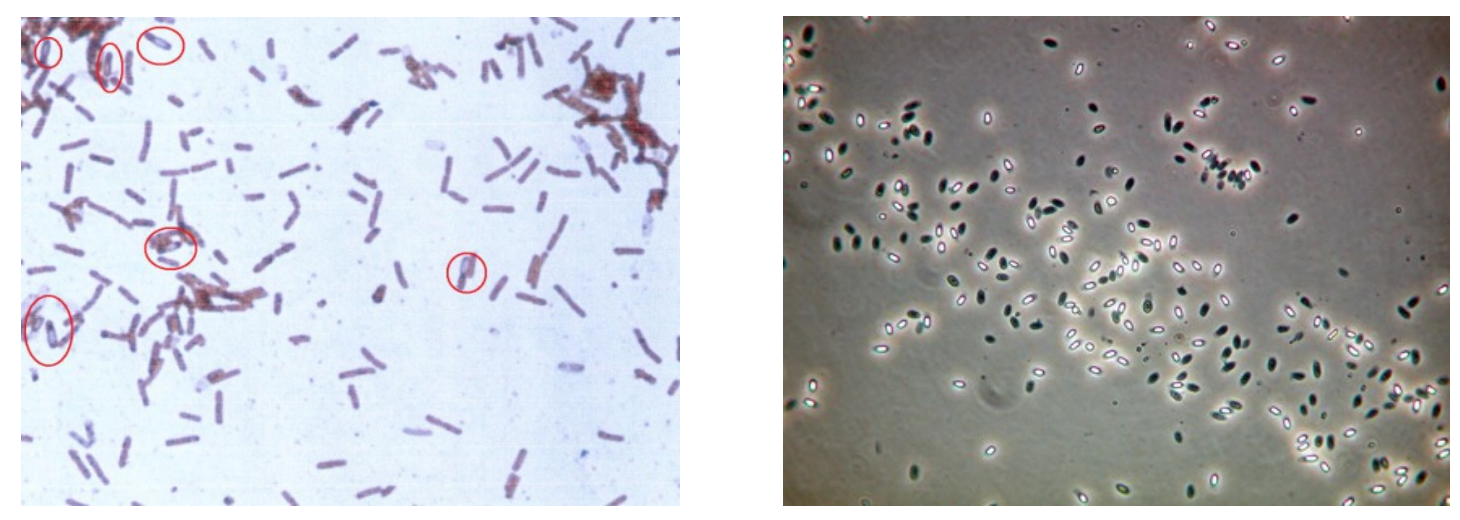

Plate 1 \& 2 Microscopic view of Bacillus cereus AK1968 and its spores
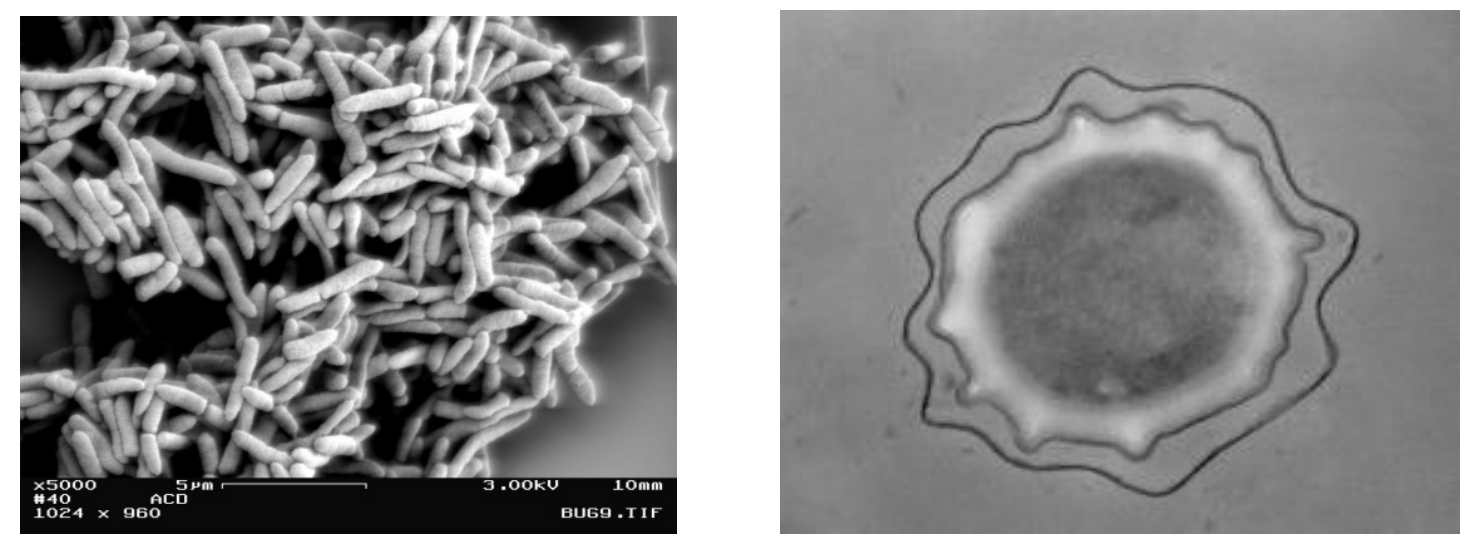

Plate 3 \& 4 Electron miocrograph of Bacillus cereus AK1968 and its spore
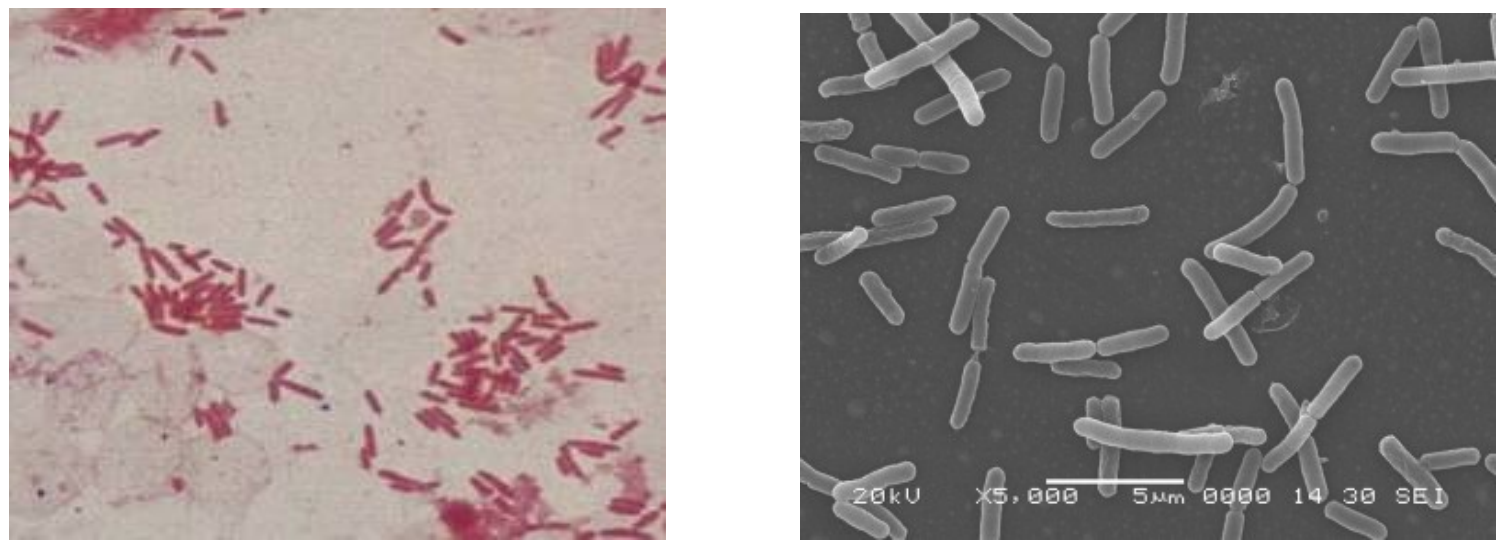

Plate 5\&6 Microscopic view and Electron micrograph of Pseudomonas sp. AKDYE14 